\title{
Clinicopathological characteristics of De Garengeot hernia: six case reports and literature review
}

\author{
Shigeaki Tsuruta ${ }^{1}$, Hideo Miyake ${ }^{1}$, Hidemasa Nagai ${ }^{1}$, Yuichiro Yoshioka' ${ }^{1}$, Norihiro Yuasa ${ }^{1 *}$ (i) \\ and Masahiko Fujino ${ }^{2}$
}

\begin{abstract}
Background: De Garengeot hernia, wherein the appendix is present within a femoral hernia, is a rare disease; therefore, the clinicopathological features remain to be clarified. This study aimed to reveal the clinicopathological characteristics of De Garengeot hernia.
\end{abstract}

Case presentation: Six patients who underwent appendectomy and herniorrhaphy between 1999 and 2018 were included. The incidence of De Garengeot hernia was 3.2\% among the 182 femoral hernias that required surgery during the study period. The median age of the patients was 78 years, and five patients were women. The median body mass index was 20.1. Patients frequently had fever or elevated CRP level. Preoperative diagnoses based on computed tomography were femoral $(n=3)$, inguinal $(n=2)$, and De Garengeot $(n=1)$ hernias. Emergency and elective surgeries were performed in four and two patients, respectively. Histopathological examination of the resected appendix showed gangrenous appendicitis $(n=3)$, perforated appendicitis $(n=2)$, and appendiceal ischemia $(n=1)$ in the patients. Postoperatively, one patient developed sepsis.

Conclusions: Preoperative diagnosis of De Garengeot hernia is often difficult, and patients frequently have severe appendicitis. Precise diagnosis is required, and emergency surgery should be considered depending on the severity of appendicitis.

Keywords: De Garengeot hernia, Femoral hernia, Appendix

\section{Background}

De Garengeot hernia is diagnosed when the content of a femoral hernia is the appendix [1]. Preoperative diagnosis remains challenging, as it is a rare disease. In addition, surgical procedures depend on the preoperative diagnosis, severity of appendicitis, and abscess formation. There are limited reports of more than three cases of the condition collectively in a single institution [2-4]; therefore, the clinical characteristics and problems associated with diagnosis and treatment have not been fully clarified.

\footnotetext{
*Correspondence: nyuasa0257@gmail.com

${ }^{1}$ Department of Gastrointestinal Surgery, Japanese Red Cross Nagoya First Hospital, 3-35 Michishita-cho, Nakamura-ku, Nagoya 453-8511, Japan Full list of author information is available at the end of the article
}

\section{Case presentation}

A review of the prospective hernia database in our department identified six cases of De Garengeot hernia (3.2\%) among 182 cases of femoral hernia that required herniorrhaphy during a 20-year period between January 1999 and December 2018. Table 1 presents the background and clinicopathological factors including age, sex, body mass index (BMI), body temperature, white blood cell (WBC) count, serum C-reactive protein (CRP) level, preoperative diagnosis, surgical procedures, histopathological findings of the resected appendix, postoperative complications, and hospital stay.

Continuous variables were expressed as mean $\pm \mathrm{SD}$ or median (IQR) as appropriate. Normality was assessed by Shapiro-Wilk test. We used JMP version 10 (SAS 
Table 1 Patient background and clinicopathological factors

\begin{tabular}{|c|c|c|c|c|c|c|}
\hline Case & 1 & 2 & 3 & 4 & 5 & 6 \\
\hline Age & 92 & 67 & 71 & 88 & 85 & 71 \\
\hline Sex & Female & Female & Female & Female & Female & Male \\
\hline Body mass index & 16.6 & 23.5 & 23.9 & 18.3 & 21.9 & 15.8 \\
\hline $\begin{array}{l}\text { Body temperature } \\
\left({ }^{\circ} \mathrm{C}\right)\end{array}$ & $\mathrm{nv}$ & $\mathrm{nv}$ & 37.0 & 37.9 & 39.1 & 38.0 \\
\hline $\begin{array}{l}\text { White blood cell } \\
\text { count }(/ \mu \mathrm{L})\end{array}$ & 7000 & $\mathrm{nv}$ & 7900 & 8700 & 15,300 & 5800 \\
\hline $\begin{array}{l}\text { C-reactive protein } \\
(\mathrm{mg} / \mathrm{dL})\end{array}$ & $\mathrm{nv}$ & $\mathrm{nv}$ & 7.44 & 11.98 & 20.09 & 4.4 \\
\hline $\begin{array}{l}\text { Signs of bowel } \\
\text { obstruction }\end{array}$ & - & - & - & + & - & - \\
\hline $\begin{array}{l}\text { Preoperative diag- } \\
\text { nosis }\end{array}$ & Femoral hernia & Femoral hernia & Femoral hernia & Inguinal hernia & Inguinal hernia & De Garengeot hernia \\
\hline Timing for operation & Emergent & Within $24 \mathrm{~h}$ & Emergent & Emergent & Emergent & within $24 \mathrm{~h}$ \\
\hline Approach & Inguinal & Inguinal & Inguinal & $\begin{array}{l}\text { Inguinal and } \\
\text { abdominal }\end{array}$ & $\begin{array}{l}\text { Inguinal and } \\
\text { abdominal }\end{array}$ & Inguinal \\
\hline $\begin{array}{c}\text { Abscess in the } \\
\text { hernia sac }\end{array}$ & - & - & - & + & - & + \\
\hline Operative methods & Mesh plug & McVay & McVay & McVay & McVay & McVay \\
\hline $\begin{array}{l}\text { Pathological } \\
\text { findings of the } \\
\text { appendix }\end{array}$ & $\begin{array}{l}\text { Gangrenous appen- } \\
\text { dicitis }\end{array}$ & Ischemia & $\begin{array}{l}\text { Gangrenous appen- } \\
\text { dicitis }\end{array}$ & $\begin{array}{l}\text { Perforated appen- } \\
\text { dicitis }\end{array}$ & $\begin{array}{l}\text { Gangrenous appen- } \\
\text { dicitis }\end{array}$ & $\begin{array}{l}\text { Perforated appen- } \\
\text { dicitis }\end{array}$ \\
\hline $\begin{array}{l}\text { Postoperative com- } \\
\text { plications }\end{array}$ & - & - & - & $\begin{array}{l}\text { Peritonitis, sepsis, } \\
\text { DIC }\end{array}$ & SSI & - \\
\hline $\begin{array}{l}\text { Postoperative hospi- } \\
\text { tal stay (days) }\end{array}$ & 9 & 10 & 8 & 29 & 23 & 8 \\
\hline
\end{tabular}

DIC disseminated intravascular coagulation, SSI surgical site infection, $n v$ not varidated

Institute Inc., Cary, NC, USA) to perform statistical procedures.

\section{Patient background}

The median age of the patients was 78 years (interquartile range: IQR 70-89) and five patients were women. The median BMI was $20.1 \mathrm{~kg} / \mathrm{m}^{2}$ (IQR 16.4-23.6). The median body temperature was $38.0{ }^{\circ} \mathrm{C}$ (IQR 37.2-38.8) in four patients whose records were available. The median WBC count was $7900 / \mu \mathrm{L}$ (IQR 6400-12,000). The median CRP level was $9.7 \mathrm{mg} / \mathrm{dL}$ (IQR 5.2-18.1) in four patients whose records were available.

\section{Preoperative diagnosis base on CT}

Preoperative computed tomography $(\mathrm{CT})$ was performed in all patients (Fig. 1), which revealed femoral $(n=3)$, inguinal $(n=2)$, and De Garengeot $(n=1)$ hernias. Retrospective review of the $\mathrm{CT}$ images indicated a tubular structure surrounded by or along with high/iso/low-density masses on the ventral and medial sides of the femoral vein in all patients (Fig. 1a-f). Figures $1 \mathrm{f}$ and 2 show $\mathrm{CT}$ images of Case 6, which could be preoperatively diagnosed as De Garengeot hernia. The axial image shows a low-density ovoid lesion with a high-density capsule and a tubular structure on the ventral and medial sides of the femoral vein, which indicates an abscess and the appendix, respectively (Fig. 1f). On the other hand, the coronal image shows an isodense blind-ended tubular structure originating from the cecum (Fig. 2).

\section{Surgical procedure}

Emergency surgery was performed in four patients and elective surgery (within $24 \mathrm{~h}$ of presentation) was performed in two patients. The surgical approach was inguinal in all cases; however, an additional abdominal incision was made in two patients. Intraoperatively, an abscess was observed within the hernia sac in two patients (cases 4 and 6, Fig. 1d, f). Appendectomy was performed in all patients. Herniorrhaphy was performed by the McVay method in five patients and the mesh plug method in one patient.

\section{Histology of the resected appendix}

Histopathological examination of the resected specimens showed gangrenous appendicitis, wherein inflammatory cells invaded the appendix with destruction of the wall architecture in three patients, perforated appendicitis in 

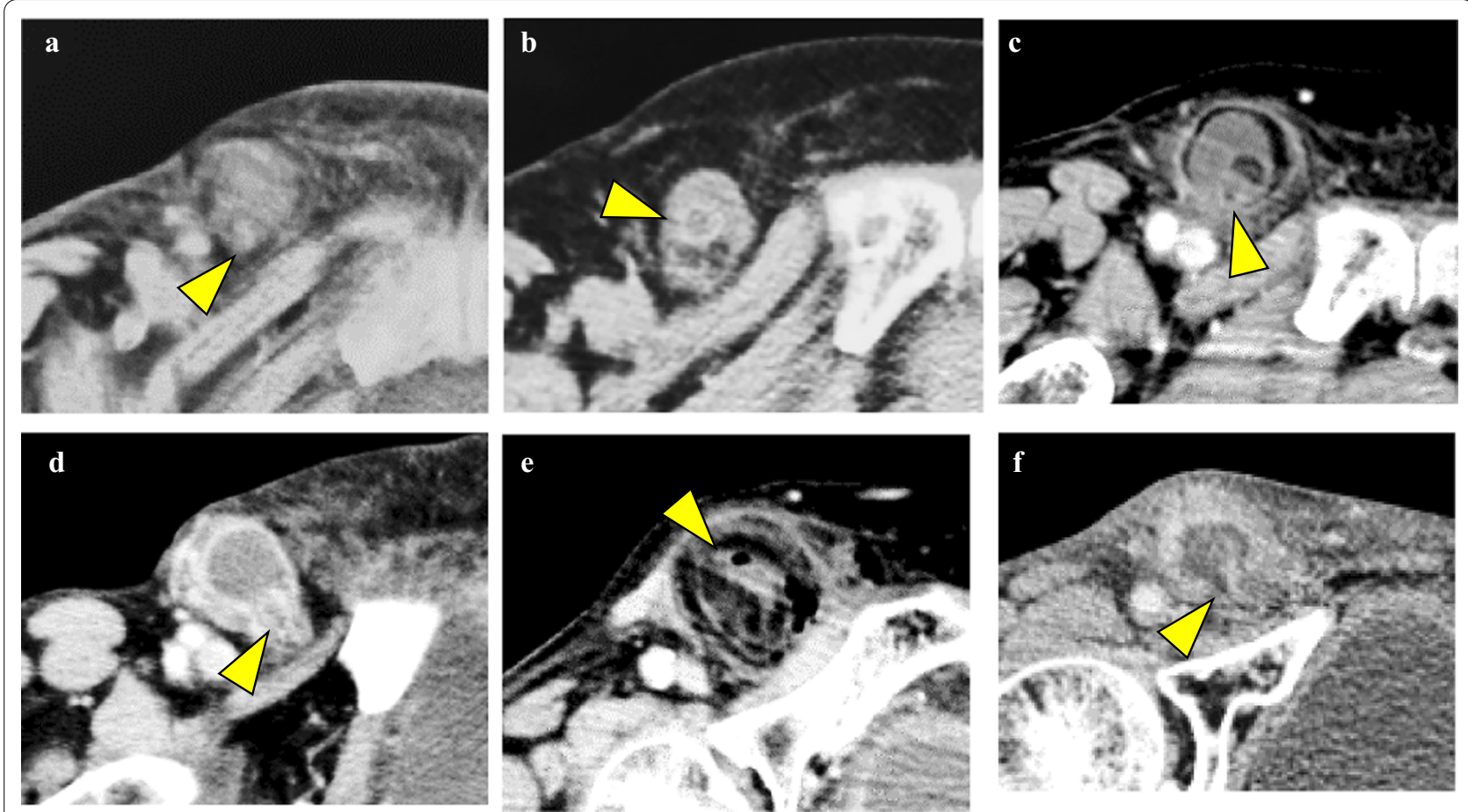

Fig. 1 Axial images of contrast enhancement CT showing a tubular structure (arrowhead) surrounded by or along with high/iso/low-density masses on the ventral and medial sides of the femoral vein in Cases 1-6 (a-f in this order). d, f: A low-density ovoid lesion with high-density capsule suggestive of an abscess around the appendix. e: A honeycomb-like low-density mass surrounding a tubular structure suggestive of the greater omentum

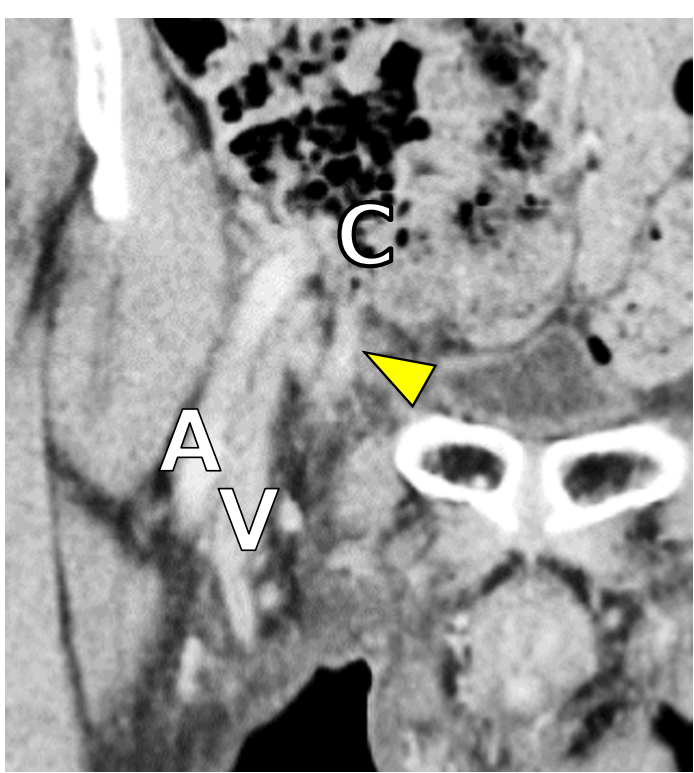

Fig. 2 Coronal image of contrast enhancement CT showing a blind-ended tubular structure (arrowhead) on the medial side of the femoral vein, which is continuous with the cecum (C). A: femoral artery, $\mathrm{V}$ : femoral vein two patients, and appendiceal ischemia in one patient (Fig. 3).

\section{Postoperative course}

One patient with perforated appendicitis and diffuse peritonitis developed postoperative sepsis and disseminated intravascular coagulation (case 4). Surgical site infection (SSI) was observed in one patient (case 5), and the median length of postoperative hospital stay was 10 days (IQR 8-25), without in-hospital death.

\section{Discussion}

This study showed the clinicopathological findings of six cases of De Garengeot hernia, and revealed that the condition occurred frequently in elderly women. Furthermore, the hernia was often associated with fever and elevated CRP levels. Precise diagnosis of the condition was rare and elective surgery was performed occasionally. One-third of the patients had perforated appendicitis. Postoperative complications included SSI and sepsis, which prolonged the duration of hospital stay.

The incidence of De Garengeot hernia has been reported as $0.15-5 \%$ of all femoral hernias [3, 5-7]. Forward movement of the appendix into the femoral canal, possibly due to the mobile cecum, the giant cecum 

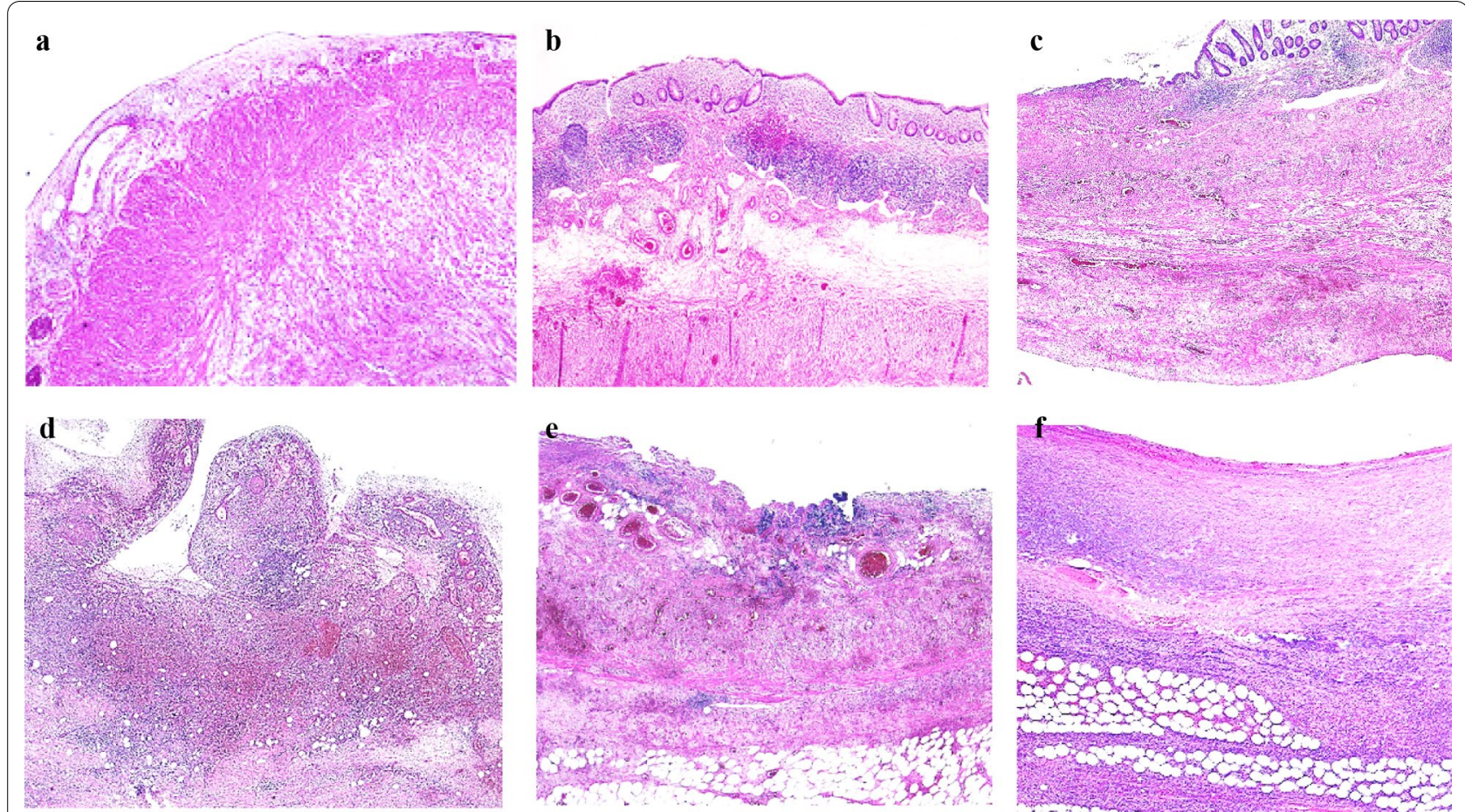

Fig. 3 Histopathological images of the appendix in cases 1-6 (a-f in this order). Inflammatory cells invading the appendiceal wall with destruction of the wall architecture indicating gangrenous appendicitis (a, c, d-f). Macroscopically, the appendix was perforated in cases 4 and 6 (d, f). Venous dilatation and thrombosis indicate appendiceal congestion (c, e). Venous thrombosis and submucosal edema indicate ischemia (b)

extending into the pelvis, or increased abdominal pressure has been hypothesized as the cause of De Garengeot hernia. Obstruction of the appendiceal lumen and impaired blood circulation or venous congestion is likely to induce bacterial growth within the lumen and cause ischemic changes in the appendiceal wall. The pathological findings of the six cases in this study supported this mechanism.

Our study showed that the preoperative diagnostic rate of De Garengeot hernia was insufficient $(17 \%, 1 / 6)$, which is in line with that reported in previous studies [8, 9]. This could be due to the rarity of the disease, affecting the ability of the surgeon to interpret the CT images. However, increased diagnostic ability has been observed due to a recent surge in the recognition of cases of De Garengeot hernia by surgeons as well as advances in CT technologies, including thin-slice, coronal, and/or sagittal images. There are three key points in the CT diagnosis of De Garengeot hernia. First, a tubular structure should be identified on the ventral and medial sides of the femoral vein. Second, the tubular structure should be continuous with the bowel (cecum) in the abdominal cavity. Third, the tubular structure should have a blind end.

Our extensive search of Japanese literature (19962020) revealed 45 cases of De Garengeot hernia, including the patients in our case series (Table 2) [10-47]. The median age of the patients was 77 years (IQR 71-83), and $84 \%$ were women. The mean BMI was $18.2 \pm 2.8$. The most frequent symptom was a mass in the groin followed by groin pain, and signs of bowel obstruction were infrequent. The median WBC count was $6238 / \mu \mathrm{L}$ (IQR $8195-12,128)$, and median value of CRP was $2.2 \mathrm{mg} / \mathrm{dL}$ (IQR 0.6-6.5). Increased WBC and CRP levels could be markers to estimate the severity of appendiceal inflammation and/or abscess formation. Correct preoperative diagnosis was made in $47 \%$ of the patients by CT and/or ultrasonography (US) $[13,17,20,24,26,29,30,32,33$, $37-46]$. Emergency surgery was performed in $88 \%$ of the patients. The McVay procedure was most commonly performed (43\%) [10,13, 14, 16, 17, 19, 21, 23, 29, 30, 34, $35,37,44]$, followed by the mesh and plug [12, 18, 22, 25, $27,33]$, Kugel patch [28, 40,45,46], suture of the femoral canal techniques [11, 15, 24, 47], and laparoscopic procedures including the transabdominal preperitoneal [39, $43]$ and totally extraperitoneal approaches [26, 32]. The advantages of the laparoscopic approach lie in the ability to explore the content of the hernia and reduce the incarcerated organs under direct vision. Furthermore, the procedure is minimally invasive [48]. Intraoperatively, periappendiceal abscess and appendiceal perforation were found in $22 \%[13,15,17,20,21,34,41]$ and $9 \%[14,17]$ of the patients, respectively. The incidence 
Table 2 Forty-five cases with De Garengeot hernia reported in Japanese literature

\begin{tabular}{|c|c|}
\hline Age & Median 77 (IQR 71-83) \\
\hline Male:Female & $7: 38$ \\
\hline Body mass index & Median 20.4 (IQR 18.1-21.7) \\
\hline Laterality of hernia (right:left) & $45: 0$ \\
\hline \multicolumn{2}{|l|}{ Symptom } \\
\hline Groin mass & $35(78 \%)$ \\
\hline Groin pain & $22(49 \%)$ \\
\hline Abdominal pain & $5(11 \%)$ \\
\hline Bowel obstruction & $2(4 \%)$ \\
\hline White blood cell count $(/ \mu \mathrm{L})$ & $9052 \pm 4075$ \\
\hline C-reactive protein (mg/dL) & $2.2(\mathrm{IQR} 0.4-6.5)$ \\
\hline Correct preoperative diagnosis & $21(47 \%)$ \\
\hline \multicolumn{2}{|l|}{ Diagnostic modalities } \\
\hline CT & $38(84 \%)$ \\
\hline US & $23(51 \%)$ \\
\hline$x-p$ & $2(4 \%)$ \\
\hline MRI & $1(2 \%)$ \\
\hline \multicolumn{2}{|l|}{ Surgical emergency } \\
\hline Emergent & $37(88 \%)$ \\
\hline Elective & $5(12 \%)$ \\
\hline \multicolumn{2}{|l|}{ Surgical procedure } \\
\hline McVay & $19(43 \%)$ \\
\hline Mesh and plug & $7(16 \%)$ \\
\hline Kugel patch & $4(9 \%)$ \\
\hline Suture of the femoral canal & $4(9 \%)$ \\
\hline $\begin{array}{l}\text { Prolene hernia system/ultrapro hernia } \\
\text { system }\end{array}$ & $3(7 \%)$ \\
\hline $\begin{array}{l}\text { Transabdominal preperitoneal approach } \\
\text { (TAPP) }\end{array}$ & $2(5 \%)$ \\
\hline Totally extraperitoneal approach & $2(5 \%)$ \\
\hline Staged surgery (mesh/TAPP) & $2(5 \%)$ \\
\hline Moschcowitz repair & $1(2 \%)$ \\
\hline \multicolumn{2}{|l|}{ Intraoperative findings } \\
\hline Periappendiceal abscess & $10(22 \%)$ \\
\hline Appendiceal perforation & $4(9 \%)$ \\
\hline \multicolumn{2}{|l|}{ Appendiceal pathology } \\
\hline Congestion\Ischemia & $9(20 \%)$ \\
\hline Catarrhal appendicitis & $8(18 \%)$ \\
\hline Phlegmonous appendicitis & $7(16 \%)$ \\
\hline Gangrenous appendicitis & $20(44 \%)$ \\
\hline Chronic appendicitis & $1(2 \%)$ \\
\hline \multicolumn{2}{|l|}{ Postoperative complication } \\
\hline Surgical site infection & $6(13 \%)$ \\
\hline Sepsis & $1(2 \%)$ \\
\hline Postoperative hospital stay (days) & Median 9 (IQR 7-12) \\
\hline
\end{tabular}

of perforation was similar to that reported in a study by Linder et al. on 90 patients reported English literature [9]. Histopathological diagnoses of the resected appendix were gangrenous appendicitis, congestion/ischemia, catarrhal appendicitis, and phlegmonous appendicitis in $44 \%, 20 \%, 18 \%$, and $16 \%$ of the patients, respectively. Thirteen percent of the patients developed postoperative SSI $[11,14,15,17,19]$, which led to prolongation of hospital stay.

There is no standard approach for the treatment of De Garengeot hernia. Appendectomy and concurrent herniorrhaphy are the treatments tailored based on severity of the appendicitis, patient condition, and surgeon's preference. Mesh material has not been recommended in the presence of abscess and/or perforation, and staged surgery, laparoscopic appendectomy, or hernioplasty via the anterior approach could be an option in such cases [48, 49].

Hence, Amyand hernia is defined as an inguinal hernia, containing the appendix within the hernia sac. Because De Garengeot hernia and Amyand hernia have each clinical characteristic, the clinical differences among De Garengeot hernia, femoral hernia and Amyand hernia are presented in Table 3 [50-52]. The incidence is comparable between De Garengeot hernia and Amyand hernia; however, the rate of appendicitis is higher in De Garengeot hernia than Amyand hernia (80\% in 45 cases of our review in Japanese literature and $92.8 \%$ in 222 cases of worldwide literature review [52]). Of note, Guenther TM et al. reported that the incidence of any one of following gross appearance of the appendix including necrosis, perforation, abscess, or fistula was 42\% [50]. De Garengeot hernia is female elderly predominant, while Amyand hernia is often associated with male elderly. Preoperative differential diagnosis can be made by image modality including CT: When a blind-ending tubular structure continuous with the cecum is located on the ventral and medial sides of the femoral vein within the femoral canal, the diagnosis is De Garengeot hernia. On the other hand, the tubular structure is located within the inguinal canal, the diagnosis is Amyand hernia.

Guenther TM et al. proposed a classification of De Garengeot hernia based on gross appearance of the appendix [50]. It will prompt an adequate selection of surgical procedures. However, preoperative evaluation of the severity of appendiceal inflammation is more important. If preoperative image modality indicate inflammation of the appendix, especially necrosis and perforation of the appendix, immediate surgery without using mesh such as open repair (McVay) is recommended. When image modality suggest absence of inflammation of the appendix and the patient is clinically stable, planned surgery of laparoscopic repair using mesh such as transabdominal preperitoneal approach is recommended. Cavigli et al. reported a case of De Garengeot hernia in which US showed thickened wall and hypervascularization of 
Table 3 Clinical difference among De Garengeot hernia, femoral hernia and Amyand hernia

\begin{tabular}{|c|c|c|c|}
\hline & De Garengeot hernia & Femoral hernia & Amyand hernia \\
\hline Hernia orifice & Femoral canal & Femoral canal & $\begin{array}{l}\text { Internal inguinal ring or posterior of the } \\
\text { inguinal canal }\end{array}$ \\
\hline Hernia content & Appendix & Any organ & Appendix \\
\hline Incidence & $0.15-5 \%$ in femoral hernia & $<10 \%$ of all groin hernias & $1 \%$ of inguinal hernia \\
\hline Incidence of appendicitis & $80-92.8 \%$ & - & $0.1 \%$ \\
\hline Age & Elderly & Elderly & Neonates and elderly \\
\hline Sex & Female predominant & Female predominant & Male predominant \\
\hline Blood examination & $\begin{array}{l}\text { elevated WBC and CRP in case with } \\
\text { appendicitis }\end{array}$ & not specific & $\begin{array}{l}\text { WBC and CRP inconsistently associ- } \\
\text { ated with the status of the vermiform } \\
\text { appendix }\end{array}$ \\
\hline CT findings & $\begin{array}{l}\text { A tubular structure: } \\
\text { (1) On the ventral and medial sides of the } \\
\text { femoral vein, } \\
\text { (2) Continuous with the bowel (cecum) in } \\
\text { the abdominal cavity, } \\
\text { (3) With a blind end }\end{array}$ & $\begin{array}{l}\text { Abdominal organ on the ventral } \\
\text { and medial sides of the femoral } \\
\text { vein }\end{array}$ & $\begin{array}{l}\text { A tubular structure } \\
\text { on medial or lateral sides of the inferior } \\
\text { epigastric vessels within the inguinal } \\
\text { canal }\end{array}$ \\
\hline Surgical emergency & Often required & Often required & $\begin{array}{l}\text { Inidicated if the appendicitis is preopera- } \\
\text { tively diagnosed }\end{array}$ \\
\hline
\end{tabular}

the appendix and hyper echoic omental fat, suggesting inflammation of the appendix without necrosis [53]. The thickness and layers of the appendiceal wall can be evaluated with US. In addition, Doppler US can reveal vascularity of the appendix.

The present case reports has several limitations. First, despite recording the data of six patients with this rare disease, several clinical factors including body temperature, WBC count, and CRP levels could not be obtained due to the prolonged study duration. Second, multidetector CT was introduced in 2007 at our institution, which enabled presentation of finer images as well as coronal and sagittal images. However, three patients who were included in the early study period did not undergo this investigation. As described previously (Fig. 2), the diagnostic sensitivity can be improved by increasing the effectiveness of CT image acquisition and reconstruction [54]. Third, we retrospectively reviewed preoperative CT images; however, US images were not fully investigated due to limited experience. The advantages of US are that the technique is non-invasive and repeatable, and shows superior discriminability due to high spatial resolution. US could facilitate correct preoperative diagnosis of De Garengeot hernia and assessment of the severity of appendicitis $[53,55,56]$.

\section{Conclusion}

De Garengeot hernia must be suspected and CT images must be carefully interpreted in patients with a groin mass and pain, as well as elevated WBC count and CRP level. De Garengeot hernia is often associated with severe acute appendicitis, and emergency surgery should be considered depending on the severity of appendicitis.

\section{Abbreviations}

CT: Computed tomography; BMI: Body mass index; WBC: White blood cell; CRP: C-reactive protein; SSI: Surgical site infection; IQR: Interquartile range; US: Ultrasonography.

\section{Acknowledgements \\ Not applicable.}

\section{Authors' contributions}

ST wrote the manuscript. NY helped to draft the manuscript. HM, HN, and YY performed the surgery. MFperformed histopathological examination. All authors read and approved the final manuscript.

\section{Funding}

This work is supported by Japanese Red Cross Nagoya First Hospital Research Grant to ST. The funder had no role in the study design, data collection, data analysis, decision to publish, or preparation of the manuscript.

\section{Availability of data and materials \\ Data sharing is not applicable to this article.}

\section{Ethics approval and consent to participate}

The study protocol was reviewed and approved by the institutional review board of the Japanese Red Cross Nagoya First Hospital. The patient's consent was obtained by the opt-out method in this retrospective observational study.

\section{Consent for publication}

Informed consent was obtained from the patients for publication of this case report and accompanying images.

\section{Competing interests}

The authors declare that they have no competing interests.

\section{Author details}

${ }^{1}$ Department of Gastrointestinal Surgery, Japanese Red Cross Nagoya First Hospital, 3-35 Michishita-cho, Nakamura-ku, Nagoya 453-8511, Japan.

${ }^{2}$ Department of Cytology and Molecular Pathology, Japanese Red Cross 
Nagoya First Hospital, 3-35 Michishita-cho, Nakamura-ku, Nagoya 453-8511, Japan.

Received: 9 October 2020 Accepted: 23 December 2020

Published online: 11 January 2021

\section{References}

1. de Garengeot RJC. Traite des operations de chirurgie. 2nd ed. Paris: Huart; 1731 , p. 369-71

2. Thomas WE, Vowles KD, Williamson RC. Appendicitis in external herniae. Ann R Coll Surg Engl. 1982;64(2):121-2.

3. Sharma H, Jha PK, Shekhawat NS, et al. De Garengeot hernia: an analysis of our experience. Hernia. 2007;11(3):235-8.

4. Dulskas A, Varanauskas G, Stasinskas A, et al. De Garengeot hernia: does the time to operation matters? An analysis of our experience. Int J Colorectal Dis. 2015;30(1):141-2.

5. Akopian G, Alexander M. De Garengeot hernia: appendicitis within a femoral hernia. Am Surg. 2005;71(6):526-7.

6. Priego P, Lobo E, Moreno I, et al. Acute appendicitis in an incarcerated crural hernia: analysis of our experience. Rev Esp Enferm Dig. 2005;97(10):707-15.

7. Gurer A, Ozdogan M, Ozlem N, et al. Uncommon content in groin hernia sac. Hernia. 2006;10(2):152-5.

8. Kalles V, Mekras A, Mekras D, et al. De Garengeot's hernia: a comprehensive review. Hernia. 2006;17(2):177-82.

9. Linder S, Linder G, Månsson C. Treatment of de Garengeot's hernia: a meta-analysis. Hernia. 2019;23(1):131-41.

10. Nagasawa K, Hasegawa H, Ogiso S, et al. A case of incarceration of the femoral hernia of phlegmonous appendix. J Jpn Soc Clin Surg. 1996:57:194-6 ((in Japanese with English abstract)).

11. Ohishi A, Kawada N, Matsuno T, et al. A surgical case report of incarcerated appendix in a femoral hernia. J Clin Surg. 1996;51:229-32 ((in Japanese))

12. Iki I, Nogami A, Kiyama A. A case of femoral hernia with incarceration of the appendix. J Hyogo Medi Assoc. 2000;43:26-8 ((in Japanese with English abstract))

13. Takemura M, Iwamoto K, Goshi S, et al. Strangulated femoral hernia containing gangrenous appendicitis: report of a case. J Jpn Coll Surg. 2000;25(5):789-91 ((in English))

14. Yamamoto N, Tachibana S, Nakamura M, et al. A case of gallbladder torsion after the operation of femoral hernia with incarceration of the appendix with past history of inguinal and obturator hernia. J Clin Surg. 2001;56:821-4 ((in Japanese)).

15. Saito $S$, Kojima M, Shimizu A, et al. A case report of femoral hernia with incarceration of the appendix with abscess formation. J Clin Surg. 2004:59:371-4 ((in Japanese)).

16. Suganuma T, Hase K, Shikina A, et al. A case of obturator hernia with femoral hernia containing the appendix. J J.pn Soc Clin Surg. 2004;57:194-6 ((in Japanese with English abstract))

17. Ohsako T, Usui T, Nishida S, Shirono K. Gangrenous appendicitis in incarcerated femoral hernia. Jpn J Gastroenterol Surg. 2005:38:701-5 ((in Japanese with English abstract)).

18. Teraoka H, Takeuchi K, Sakurai K, et al. A case of femoral hernia with incarceration of the appendix. Jpn J Gastroenterol Surg. 2005;38:98-101 ((in Japanese with English abstract)).

19. Umeoka T, Sakai K, Isozaki H, et al. A case of strangurated femoral hernia containing the gangrenous appendix. J Jpn Soc Clin Surg. 2005;66:2740-3 ((in Japanese with English abstract)).

20. Hiraga M, Nakamura K, Sakaguchi Y, et al. Flow disturbance in the femoral vein in a case of femoral hernia containing appendices. Jpn J Med Ultrasonics. 2006;33:363-8 ((in Japanese with English abstract)).

21. Mizusaki K, Saito E. A case of femoral hernia with incarceration of the phlegmonous appendix. Jpn J Gastroenterol Surg. 2006;39:1741-6 ((in Japanese with English abstract)).

22. Araki M, Takebe K, Ohsawa K, et al. A case of femoral hernia with incarcerated appendix. Gunma Med. 2006;84:167-9 ((in Japanese)).

23. Yoshida T, Masubuchi M, Mitsumori N. Two cases of femoral hernia with incarceration of the appendix. J Jpn Soc Clin Surg. 2006;67:2109-13 ((in Japanese with English abstract)).
24. Matsutani $\mathrm{H}$, Ohishi S, Yoshizaki T, et al. A male case of femoral hernia with incarceration of the appendix. J Clin Surg. 2007;62:1123-6 ((in Japanese)).

25. Majima T, Sakakibara T. A case of incarcerated appendix in a femoral hernia. J Kyoto Pref Univ Med. 2008;117:483-8 ((in Japanese with English abstract)).

26. Ohta R, Oneyama M, Takahashi Y, et al. Laparoscopic repair of femoral hernia with incarceration of the appendix: a case report. Jpn J Gastroenterol Surg. 2009;42:1631-6 ((in Japanese with English abstract)).

27. Takagi T, Nakase Y, Fukumoto K, et al. A case of femoral hernia with incarceration of the appendix. J Jpn Soc Clin Surg. 2009;70:265-9 ((in Japanese with English abstract)).

28. Takenaga M, Yoshida I, Yamamoto T, et al. A case of femoral hernia with incarceration of the appendix. J Hyogo Surg Assoc. 2010;44:30-4 ((in Japanese)

29. Yasumoto A, Tokumura $\mathrm{H}$, Takahashi $\mathrm{K}$, et al. A case of right femoral hernia with incarceration of the appendix. J Jpn Soc Clin Surg. 2010;71:235-8 ((in Japanese with English abstract)).

30. Hasegawa K, Ishiyama T, Jingu A, et al. A preoperatively diagnosed case of incarcerated appendix in femoral hernia. Operation. 2011;65:1577-9 ((in Japanese)).

31. Sano M, Nakayama T, Shintani T, et al. Femoral hernia with incarceration of the appendix: a case report with a review of the Japanese literature. Jpn J Gastroenterol Surg. 2011;44(8):1055-61 ((in Japanese with English abstract)).

32. Matsukawa S, Shiratori T, Kugimiya M, et al. A case in which laparoscopic totally extraperitoneal approach and appendectomy were performed for preoperatively diagnosed incarcerated appendix within femoral hernia. Operation. 2012;66:1299-302 ((in Japanese)).

33. Deguchi $\mathrm{K}$, Obayashi T, Ueda H, et al. A case of right femoral hernia with incarceration of the appendix. J Jpn Soc Clin Surg. 2013;74:1096-100 ((in Japanese with English abstract)).

34. Miyata T, Tsukada T, Mawatari T, et al. A case of a man with femoral hernia involving incarceration of the appendix. J Jpn Soc Clin Surg. 2013;74:1997-2001 ((in Japanese with English abstract)).

35. Miyatani K, Hanaki T, Yamamoto $O$, et al. A case of femoral hernia with incarceration of the appendix. J Jpn Soc Clin Surg. 2013;74:2325-30 ((in Japanese with English abstract))

36. Mizuno T, Kawabe A, Okumura T, et al. A case of femoral hernia with incarceration of the appendix identified in abdominal CT. J Jpn Soc Clin Surg. 2014;75:1730-4 ((in Japanese with English abstract)).

37. Nonoyama K, Hayakawa T, Nakamura K, et al. Two cases of De Garengeot's hernia. J Jpn Soc Clin Surg. 2014;75:2903-8 ((in Japanese with English abstract)).

38. Saito Y, Otani S, Sato Y, et al. A case of laparoscopic repair of a femoral hernia with incarceration of the appendix. J Jpn Soc Clin Surg. 2014;75:260612 ((in Japanese with English abstract)).

39. Takadate T, Nakagawa K, Suzuki H, et al. Laparoscopic repair of femoral hernia with incarceration of the appendix: a case report. Med J Sendai Red Cross Hosp. 2014;23:43-7 ((in Japanese))

40. Murakawa A, Matsumoto S, Shimizu M, et al. A case of femoral hernia with incarceration of appendix vermiformis. J Abd Emerg Med. 2015:35:171-5 ((in Japanese with English abstract))

41. Nonoyama K, Nakamura K, Kitagami H, et al. A case of de Garengeot hernia with abscess treated with TAPP procedure after laparoscopic appendectomy. J Jpn Soc Endosc Surg. 2015;20:261-7 ((in Japanese with English abstract)).

42. Murotani T, Sugimoto S, Miyazaki Y, et al. A case of De Garengeot hernia. J Jpn Soc Clin Surg. 2016;77:3034-40 ((in Japanese with English abstract)).

43. Yoshida R, Matsukuma A, Maruyama S, et al. A case of laparoscopic repair of a femoral hernia with an incarcerated appendix. J Jpn Soc Clin Surg. 2017;78:156-61 ((in Japanese with English abstract))

44. Yoshida K, Mitsui H, Kanazawa N, et al. A preoperatively diagnosed case of an incarcerated appendix in femoral hernia. J Clin Surg. 2017;72:1013-7 ((in Japanese))

45. Atsuta K, Kobayashi J, Odani E, et al. A case of De Garengeot hernia diagnosed preoperatively. J Shizuoka Red Cross Hosp. 2017;37:1-5 ((in Japanese with English abstract)).

46. Uchino Y, Naritomi K, Ureshino H, et al. A case of de Garengeot's hernia that could underwent one-stage surgery by using laparoscope and 
anterior approach method. J Kurume Med Assoc. 2018;81:67-72 ((in Japanese with English abstract)).

47. Ueda $\mathrm{M}$, Ikenaga $\mathrm{M}$, Itakura $\mathrm{H}$, et al. A case of incarcerated femoral hernia of the small intestine and appendix. J Jpn Coll Surg. 2018;43:952-8 ((in Japanese with English abstract)).

48. Rollo A, Franzini C, Casali L, et al. De Garengeot hernia: laparoscopic treatment in emergency. Acta Biomed. 2019;90:568-71.

49. Shiihara M, Kato T, Kaneko Y, et al. De Garengeot hernia with appendicitis treated by two-way-approach surgery: a case report. J Surg Case Rep. 2017. https://doi.org/10.1093/jscr/rjx140.

50. Guenther TM, Theodorou CM, Grace NL, et al. De Garengeot hernia: a systematic review. Surg Endosc. 2020. https://doi.org/10.1007/s0046 4-020-07934-5.

51. Dahlstrand U, Wollert S, Nordin P, et al. Emergency femoral hernia repair: a study based on a national register. Ann Surg. 2009;249:672-6. https://doi. org/10.1097/SLA.0b013e31819ed943.

52. Michalinos A, Moris D, Vernadakis S. Amyand's hernia: a review. Am J Surg. 2014;207:989-95. https://doi.org/10.1016/j.amjsurg.2013.07.043.
53. Cavigli E, Mastrorosato M, Danti G, et al. Ultrasound diagnosis of acute appendicitis complicating De Garengeot's hernia. J Ultrasound. 2020. https://doi.org/10.1007/s40477-020-00466-7.

54. Fukukura Y, Chang SD. Acute appendicitis within a femoral hernia: multidetector CT findings. Abdom Imaging. 2005;30:620-2.

55. Abdulghaffar S, Almulla M, Gupta P, et al. CT and ultrasound findings in a case of De Garengeot's hernia: a case report. Radiol Case Rep. 2019;14(6):704-7.

56. Jennings L, Presley B, Jauch E. De Garengeot hernia diagnosed with point-of-care ultrasound. Clin Pract Cases Emerg Med. 2019;3:119-22.

\section{Publisher's Note}

Springer Nature remains neutral with regard to jurisdictional claims in published maps and institutional affiliations.

\section{Submit your manuscript to a SpringerOpen ${ }^{\circ}$ journal and benefit from:}

- Convenient online submission

- Rigorous peer review

- Open access: articles freely available online

- High visibility within the field

- Retaining the copyright to your article

Submit your next manuscript at $\boldsymbol{\nabla}$ springeropen.com 